\title{
The Fall of Kinship*
}

\section{Towards an Epidemiological Explanation}

\author{
Paulo SousA**
}

\begin{abstract}
Kinship used to be described as what anthropologists do. Today, many might well say that it is what anthropologists do not do. One possible explanation is that the notion of kinship fell off anthropology's radar due to the criticisms raised by Needham and Schneider among others, which supposedly demonstrated that kinship is not a sound theoretical concept. Drawing inspiration from epidemiological approaches to cultural phenomena, this article aims to enrich this explanation. Kinship became an unattractive theoretical concept in the subculture of anthropology not simply because of problems with kinship theory per se, but also on account of fundamental changes in the very conception of anthropological knowledge and the impact of these changes on the personal identity of anthropologists.
\end{abstract}

\section{KEYWORDS}

Epidemiology of representations, history of ideas, anthropology, kinship studies.

\section{Introduction}

Kinship studies once played a central role in anthropology, contributing fundamentally to its identity in the context of the social sciences (Eriksen \& Nielsen 2001; Kuper 1988). Kinship was a domain investigated almost exclusively by anthropologists (in comparison with other domains such as religion, economy and politics that were also under the focus of the other social sciences). Kinship was regarded as the central organizing principle of "primitive" societies, which were likewise the proper object of anthropological inquiry (in comparison with the "modern" societies investigated by the other social sciences). However, kinship studies have

* Many thanks to Michael Baran, Phoebe Ellsworth, Larry Hirschfeld, Webb Keane, Nicola Knight, Brian Malley, Sarah Rigg, Diego Rios, George Rosenwald, Barbara Sarnecka and Dan Sperber for their criticisms and suggestions.

** Candidate, Department of Anthropology and Culture \& Cognition program, University of Michigan. E-mail: psousa@umich.edu. 
become marginalized since the 1970s. Kinship experts have not only pointed out this decline of interest in kinship, but have also suggested some facts that may have contributed to (or at least co-occurred with) its demise:

Anthropology's love affair with kinship has cooled in recent decades (...) This trend has been construed by some observers as a clear (if not relieving) sign that the study of kinship is dead or moribund. Although such views remind one of Mark Twain's remark that reports of his death had been greatly exaggerated, they do resonate with two important changes in the status, scope and constitution of kinship studies that have occurred since the early 1970s. First, theories and debates about what were once taken to be the basic building blocks of kinship (kinship terminologies, so-called rules of descent, marriage, and postmarital residence) no longer occupy their long privileged position of centrality within the discourse of anthropology. (...) The second important change (...) refers to the fact that the study of kinship has been reconstituted and partially subsumed under other (admittedly problematic and contested) rubrics such as social history, legal anthropology, and political anthropology, and (...) feminist anthropology. (Peletz 1995: 345)

In the last ten to fifteen years, anthropology has undergone a definite shift away from traditional approaches to the study of kinship, formerly one of its central concerns. Initially, this was occasioned by statements that there is really no such thing as kinship, at least comparatively speaking, and that only by giving our attention almost exclusively to indigenous categories can anything worthwhile be said on the matter. Later, kinship came to be subsumed more and more under studies into gender, personhood, the body, ritual etc. - something reflecting this very same anti-formalist tendency. (...) quite a number of anthropologists, refusing to be either seduced or browbeaten by the insistence of some of their colleagues that there is no such thing as kinship, have persisted in developing traditional approaches, with many fruitful results. (Parkin 1997: Preface)

The major theorists of anthropology made their mark in the study of kinship. It seemed more or less impossible to imagine what anthropology would look like without kinship. And yet from the 1970s on, the position of kinship as a field of study within anthropology has been under question. (...) It has become standard, in works on kinship published since the 1980s, for gender, the body, and personhood to feature prominently in the analysis, while relationship terminologies are barely referred to, and kinship diagrams scarcely make an appearance. 'The kinds of problems changed.' (Carsten 2000: 2-3) 
In this article, I would like to assemble these facts in a coherent explanatory picture, by delineating an epidemiological explanation of the fall of kinship in anthropology.

Epidemiological approaches are now an influential methodological tool among cognitive anthropologists and other cognitive scientists interested in cultural phenomena (see, e.g., Atran et al. 2001; Bloch \& Sperber 2002; Boyer 2001; Hirschfeld 1995; McCauley \& Lawson 2002; Morris et al. 2001; Nichols 2002; Sperber 1996; Strauss \& Quinn 1997; Whitehouse 2000). ${ }^{1}$ The general aim is to explain the process of distribution of two classes of causally related phenomena: mental facts and public productions. By 'mental facts,' I mean the flux of mental representations such as beliefs, ideas, and values inside individual minds, which are deployed by the processes of perception, reasoning and judgment. By 'public productions,' I mean the various external productions of the mind such as behaviors, artifacts and, more specifically, public representations (e.g., utterances, images in a painting, writings in a book), which constitute the interactions individuals have with each other and are part of the environment.

Current epidemiological studies have focused mainly on why certain mental representations (and their public productions) become and remain widespread and important. ${ }^{2}$ Yet, inasmuch as the general explanandum is the process of distribution, the epidemiological rationale may be applied mutatis mutandis to explain why certain mental representations (and their public productions) cease to be widespread and important. Thus, following this reversal of motif, my goal is to explain why the idea of kinship became and remained an unsound theoretical concept in the minds of many anthropologists, with the consequent decrease of public productions such as lectures, colloquia, articles and books about kinship.

To identify the causal factors that made the concept of kinship unattractive and show how they are interrelated is the main task of an epidemiological explanation in this case. One main factor emphasized by

${ }^{1}$ In denying that imitation is the fundamental mechanism of cultural transmission, these epidemiological approaches should not be conflated with a memetic approach - neither in the meme-as-virus, nor in the meme-as-gene version. For a criticism of memetics, see Sperber 1996 (Chapter 5), 2000. For an overview of traditional memetic versions, and a new proposal, see Aunger 2002.

${ }^{2}$ Being important here should be interpreted in terms of Claudia Strauss's notion of social dominance (see Strauss 2000). 
the authors quoted above is the skeptical reappraisal of the basic conceptual framework that supported kinship studies. I describe the criticisms involved in this reappraisal in the next section. The authors also allude to alterations in the general view of anthropological knowledge as another factor ("anti-formalist tendency," "the kinds of problems have changed"). In the following section, I characterize the epistemological shift that is most relevant to explain the fall of kinship. In the final section, I formulate the epidemiological explanation by addressing how these two factors are connected, and by integrating into the explanation some additional facts highlighted above as well (e.g., the dilution of kinship themes into other areas of research, and the exaggerated claims of decreased interest in kinship).

\section{The Skeptical Dilemma}

During the 1960s, skepticisms concerning the foundation of kinship theories started to pop up. These criticisms, which heightened during the seventies, raised doubts about the very possibility of the existence of kinship theory. In this section, focusing on the possible demarcations of the basic content of kinship as a theoretical concept in anthropology, I describe the main arguments put forward by two influential "kinship skeptics" - the British anthropologist Rodney Needham and the American anthropologist David Schneider. ${ }^{3}$

Morgan, the father of kinship studies, conceptualized kinship with an explicit reference to a genealogical grid defined in biological terms:

A system of consanguinity, which is founded upon a community of blood, is but the formal expression and recognition of these [family] relationships. Around every person there is a circle or group of kindred of which such person is the center, and the Ego, from whom the degree of the relationship is reckoned and to whom the relationship itself returns. Above him are his father and mother and their ascendants, below him are his children and

\footnotetext{
${ }^{3}$ For the sake of concision, I'll neglect one aspect they have in common that reinforces their criticisms - both Needham and Schneider tend to assume a global approach to the semantics of kinship terms in the sense that they reject a division between the primary (kinship) meanings of relationship terminologies and other derivative or metaphorical meanings. See Needham (1974), Schneider (1976, 1980), and also Leach (1958, 1967) for another version of this semantic position.
} 
their descendants; while on either side are his brothers and sisters and their descendants and the brothers and sisters of his father and of his mother and their descendants as well as a much greater number of collateral relatives descended from common ancestors still more remote. A formal arrangement of the more immediate blood kindred into lines of descent, with the adoption of some method to distinguish one relative from another and to express the value of the relationship, would be one of the earliest acts of human intelligence. (Morgan 1871:10)

But from the turn of the century on, more and more anthropologists started to follow the Durkheimian argument that kinship is nothing if not social (Durkheim 1898), thus downplaying a link to biology. This more sociological orientation is well exemplified by Radcliffe-Brown's definition:

Two persons who are kin are related in one or two ways: either one is descended from the other, or they are both descended from a common ancestor. It is to be remembered that 'descent' here refers to the social relationship of parents and children, not to the physical relation. Kinship is thus based on descent, and what first determines the character of a kinship system is the way in which descent is recognized and reckoned. (RadcliffeBrown 1950: 13)

By the beginning of the sixties, it became clear though that there was some muddle in this general division between the biological and the social aspects of kinship. A debate that occurred in the Journal Philosophy of Science between the years of 1957 and 1963, among Ernest Gellner (see Gellner 1957, 1960, 1963), Rodney Needham (see Needham 1960), and John Barnes (see Barnes 1961, 1964) elucidated the issue. Gellner, in attempting to show how kinship could illustrate an ideal language in the sense of earlytwentieth-century analytic philosophers, conceived kinship as axiomatically bound to a biological grounding. Needham replied that Gellner confused biological and social relationships, and that the social aspects are the ones relevant for an anthropologist. Barnes entered the discussion claiming that three different aspects should be set apart: the true genetic genealogical relations (the real biological facts), the culturally postulated genealogical relations (folkbiological ideas about human reproduction), and the social norms that regulate kinship social relations (e.g., rules of inheritance, succession, attitude etc.). That these aspects can be neatly distinguished is underpinned by the fact that the genetic father (as the real biological father), 
the genitor (as the culturally conceived biological father), and the pater (as the one who fulfills the social role of father) need not coincide in the same individual. According to Barnes, while the first aspect is not relevant, the last two are. Gellner's rejoinder, accepting Barnes' distinctions, claims that anthropologists do indeed take for granted biology as defined within the folkbiology of their own culture.

Rodney Needham persisted with his sociological orientation:

Let me simply adopt the minimal premise that kinship has to do with the allocation of rights and their transmission from one generation to the next. These rights are not of any specific kind but are exceedingly various: they include most prominently rights of group membership, succession to office, inheritance of property, locality of residence, type of occupation, and a great deal else. They are all, however, transmissible by modes which have nothing to do with the sex or genealogical status of transmitter or recipient. Certainly they have no intrinsic connexion with the facts, or the cultural idioms, of procreation. (Needham 1971: 3-4) (Emphasis added)

However, by the beginning of the seventies, he is interested in questioning the theoretical validity of the concept of kinship in itself. The main point of Needham's criticisms of kinship studies is that anthropologists had succumbed to an undue craving for universality. ${ }^{4}$ This craving was prompted by anthropologists' misguided notion of classification, namely, the idea that a concept delimits a class of objects that share certain properties, and that this commonality constitutes the essence of the objects of the class. By attempting to subsume the variability of social phenomena into concepts or typologies whose semantic features are defining in this essentialist way, anthropologists have, according to Needham, bypassed the heterogeneity and complexity of social life.

Take the concept of marriage, for example. Marriage was defined by Leach as an association between men and women which is regulated by certain rights such as "to establish the legal father of a woman's children, to establish the legal mother of a man's children, to give the husband a monopoly in the wife's sexuality, to give the wife a monopoly in the

\footnotetext{
${ }^{4}$ His criticism furthers Edmund Leach's previous attempt to rethink anthropology (see Leach 1961a), and is inspired by the work of the "second" Ludwig Wittgenstein (see Wittgenstein 1953).
} 
husband's sexuality, to establish a joint fund of property - a partnership - for the benefit of the children of the marriage..." (see Leach 1961a: 107-108, for the complete definition). Following Leach, Needham argues that none of the rights that are part of the concept of marriage exist in all empirical instances of what anthropologists call 'marriage.' For this reason, what may constitute the commonality of the various concrete cases is simply an idea of a "contractual union of sexual statuses" (Needham 1971: 7), too vague a notion to describe anything specific to the domain of kinship. Therefore, Needham concludes that 'marriage' "is an odd-job word: very handy in all sorts of descriptive sentences, but worse than misleading in comparison and of no real use at all in analysis" (1971: 7-8).

As a second example, take the categorization of societies according to principles of descent. ${ }^{5}$ Needham understands these principles as different modes of transmitting rights and duties - e.g., in patrilineal descent, transmission on the male line; in matrilineal descent, on the female line; in cognatic descent, on both lines (Needham 1971). Furthermore, for him these modes of transmission are domain-specific in the sense that in the context of the same society different types of rights and duties can be allocated following different modes of descent - e.g., the inheritance of property being transmitted by a matrilineal principle, and group membership by a cognatic principle (Needham 1971).

\footnotetext{
${ }^{5}$ In this point, Needham also indicates an aggravating problem, viz., the absence of consensus on what 'descent' means - "(. . ) a wordy conflict of rival definitions" (Needham 1971: 45). There are three main semantic dimensions that can be used separately or combined in defining the term 'descent': (i) Ideological constructs that trace genealogical relations to common ancestors, and are conceived to be based in one way or another on folkbiological ideas about human reproduction - e.g., patrilineal descent, matrilineal descent and cognatic descent. (Here things become more complicated when an additional distinction between filiation and descent is introduced.); (ii) Social groups whose criterion of identity is normally tied to the ideological constructs just mentioned - e.g., matrilineages, patrilineages and cognatic descent groups. (Here there is also the further problem of characterizing a social group, in particular a corporate social group.); (iii) Jural rules of allocation of rights and duties - e.g., rules for the inheritance of properties or names, and for the succession to political or ritual offices. Consonant with his sociological orientation, Needham's interpretation of 'descent' disregards the first dimension and takes group membership as one additional status to be allocated, focusing hence on the third dimension. For discussions of the notion of descent in anthropology, see Dumont 1971; Fortes 1959; Kuper 1982; Rivers 1924; Scheffler 1966, 1985, 2001 b.
} 
According to Needham, anthropologists had frequently committed a double mistake in elaborating typologies based on principles of descent. As a formal illustration (Needham 1971), take three different societies (A, B, $\mathrm{C})$, each having three types of rights or duties [from the set $(p, \ldots, v)$ ] as important constituents of their social structure, and suppose $r$ and $t$ were transmitted matrilineally:

$$
\begin{aligned}
& \text { A } \\
& \text { B } p, q, r \\
& \text { C } \\
& \quad r, s, t \\
& \quad t, u, v
\end{aligned}
$$

As far as the transmission of these rights and duties is concerned, there is only a "serial likeness" among these societies - i.e., A and B are similar in relation to $r, \mathrm{~B}$ and $\mathrm{C}$ in relation to $t$, and $\mathrm{A}$ and $\mathrm{C}$ are wholly dissimilar. Yet, and here is the first mistake, anthropologists tend to arbitrarily elect the mode of transmission of certain rights and duties as the characteristic of a specific society considered as a whole - e.g., societies A, B and C each being named a matrilineal society, because $r$ and/or $t$ are elected as their characteristic mode of transmission. Then, as a second mistake, the arbitrary class of matrilineal societies, whose elements include $\mathrm{A}, \mathrm{B}$, and $\mathrm{C}$, is inductively established.

According to Needham, the undue craving for universality is also reflected in the attempt to elaborate simple laws that trace empirical correlations between kinship structure and social structure, and to posit principles that could explain the correlations thus formulated. Since this project is based on the flawed concepts and typologies just analyzed, it is obvious that it is necessarily doomed: "(...) if it is conceded that the social facts in question do not necessarily compose a conventional class of this homogeneous kind, but may instead exhibit an immense array of serial and more complex resemblances, then the grounds for this method of comparison and explanation are removed" (Needham 1971: 31).

Given these types of problems, Needham concludes more generally that kinship cannot be the object of a theory:

What information is given, then, by the report that an institution has to do with 'Kinship'? Nothing, really, about social facts. For the label designates no distinct type of phenomena; it provides no clue to comprehension; and it does not indicate the kind of analysis that will be appropriate. (...) there is 
no such thing as kinship; and it follows that there can be no such thing as kinship theory. (Needham 1971: 4-5)

David Schneider concurs with many of Needham's conclusions. However, he rejects the basis on which Needham construes the problem: he does not comply with Needham's strict sociological orientation in circumscribing the content of kinship. In relation to Barnes, he agrees that the folkbiological and the social aspects are the relevant ones, but adds that the former has priority over the latter, because any characterization of a social aspect of kinship presupposes a folkbiological reference - e.g., adoption is a kinship relationship only when the culturally postulated biological relationship is implied (Schneider 1965).

As regards Gellner, Schneider only partly agrees with his last suggestion that anthropologists take for granted folkbiology as defined within their own culture. Accordingly, Schneider argues that anthropologists in general assume that genealogical relationships are the first criterion of kinship, as if a version of Morgan's genealogical grid were the frame of a universal folkbiology. In particular, he attempts to show that those of a more sociological perspective actually implicitly assume genealogical relations as the criterion to identify kinship relationships. ${ }^{6}$ On the other hand, contrary to Gellner, Schneider sees no justification for such an assumption. And this is not simply due to an ethnocentric fault (a particular folkbiology being taken as universal), since Schneider argues that the genealogical assumption is not even adequate to describe his own culture. In other words, according to Schneider, the genealogical grid is not even part of folk American culture.

\footnotetext{
${ }^{6}$ It is interesting to notice that there is a continuum of different interpretations of kinship, as far as the content of kinship as an autonomous dimension of social structure is concerned. Some see it as a broad jural-political dimension (see Needham above), others take it simply as a strict domestic dimension (see Fortes 1959), and yet others, like Beattie (1964) and Leach (1961b), argue that kinship is rather a contentless language used to talk about other dimensions of social structure - "To say (...) that a social relationship is a kinship one is to tell us nothing at all of its content. The whole point about kinship relations for the social anthropologists is that they must be something else, for example, political, jural, economic or ritual. Kinship is the idiom in which certain kinds of political, jural, economic, etc. relations are talked and thought about in certain societies. It is not a further category of social relationships (...)" (Beattie 1964: 101-110). Even if Schneider does not mention this continuum, he suggests that all anthropologists of the more sociological tradition are subject to his criticism.
} 
In order to understand the gist of Schneider's interpretation of American "kinship," it is necessary to elucidate the type of cultural analysis that frames his approach. He distinguishes the cultural system from the normative system, each being a type of abstract dimension of human actions, and, respectively, the object of cultural analysis and sociological analysis. ${ }^{7}$ The normative system comprises the social rules and roles that guide human action, whereas the cultural system is made up of the symbols and meanings presupposed by human actions and the normative system:

By symbols and meanings I mean the basic premises which a culture posits for life: what its units consist in; how those units are defined and differentiated; how they form an integrated order or classification; how the world is structured; in what parts it consists and on what premises it is conceived to exist, the categories and classifications of the various domains of the world of man and how they relate one with another, and the world that man sees himself living in. (...) Culture takes man's position vis-à-vis the world rather than a man's position on how to get along in the world as it is given; it asks "Of what does this world consist?" where the normative level asks, "Given the world to be made up in the way it is, how does a man proceed to act in it?" Culture concerns a stage, the stage setting, and the cast of characters; the normative system consists in the stage directions for the actors and how the actors should play their parts on the stage that is so set. (Schneider 1972: 38)

Schneider also argues that there are two different levels of abstraction of the cultural system, which give the rationale for two different types of cultural analysis - the pure analysis and the conglomerate analysis. In the pure level, cultural units are analyzed distinctly and independently of any normative sub-system, that is, any particular institution. In the conglomerate level, on the other hand, cultural units are analyzed together but only to the extent that they are involved in a particular institution - the conglomerate level of analysis is called 'conglomerate' because it deals with

${ }^{7}$ By the end of the fifties, the anthropologist Alfred Kroeber and the sociologist Talcott Parsons, drawing from Parsons' theory of social action (see Parsons 1951) and reflections on previous definitions of the concept of culture (see Kroeber \& Kluckhohn 1952), put forward a manifesto where a division of labor between anthropology and sociology was delineated in order to further the scientific progress of (and the collaboration between) both disciplines (see Kroeber \& Parsons 1958). Schneider's conception of cultural analysis is an offshoot of this proposal (see Schneider 1968, 1972, 1976). 
the meaningful conjunction of various cultural units like gender, class and age in a specific institution like the family, not because it deals with the norms of the specific institution (e.g., the norm that a middle class father should earn the money to support his family), which are part of the normative system. For example, in a pure analysis, one would study the meanings and symbols of gender, age and class severally and independently of any institution like the family, the state and the church; in a conglomerate analysis, one would study the meanings and symbols of gender, age and class conjointly and insofar as they are involved in one particular institution like the family.

American "kinship" can be analyzed both at the conglomerate level and at the pure level. However, for Schneider, "kinship" is not a cultural unit at the pure level (it is not a pure cultural unit), even if it is such a unit at the conglomerate level (it is a conglomerate cultural unit identified with the institution of the family). ${ }^{8}$

In analyzing "kinship" at the pure cultural level, one is interested in the general meanings and symbols that define a person as a relative as against a non-relative. According to Schneider, there are two basic semantic features that contribute to this definition - the idea of shared bio-genetic substance and the idea of diffuse, enduring solidarity. Moreover, the combination of these features entails three basic types of relatives: blood relatives (both features being present), relatives in nature (only the first feature being present), and relatives-in-law (only the second feature being present).

However, the basic features do not establish a specific cultural unit because they are co-extensive with a general distinction that exists at the pure cultural level: the order of nature versus the order of law (in the broad sense of a domain of norms, costumes and traditions). According to Schneider, this claim is supported by the fact that at the pure level Americans do not distinguish "kinship" from other units like "nationality," which are also co-extensive with the general distinction between nature and law:

to abstract the pure [nationality] system we simply ask, What makes a person a citizen? What are the distinctive features which define a person's nationality?

${ }^{8}$ The classificatory division of the normative system in different institutional sub-systems like the family, the state, and the church is part of the cultural system (i.e., it is a classification of the different conglomerate cultural units), even if the norms of each particular institution are part of the normative system. 
He is either born an American or he is - and the word is of course quite significant - naturalized. Once again we find that the distinctive feature are shared substance (being born American) and a code for conduct which enjoins diffuse, enduring solidarity: being a loyal American, loving one's country, and, President Kennedy's felicitous phrase, "Ask not what your country can do for you. Ask rather what you can do for your country." (1972: 41)

In other words, because there is no distinction between "kinship" and "nationality" at the pure level of analysis, neither "kinship" nor "nationality" can be a specific pure cultural unit.

But couldn't someone counter-argue that the idea of shared bio-genetic substance, normally phrased as shared blood, is something more specific that, instead of having simply a discrete role of delimiting general types of relatives, also functions as a graded structure that determines genealogical distance? And couldn't one say that, after all, this calibration of the amount of common substance is just the basis of the genealogical grid supposed by Morgan?

True, as Schneider himself acknowledges, Americans talk about "kinship" in just such terms:

It is said that they can trace their blood through certain relatives, that they have "Smith blood in their veins." (...) Because blood is a "thing" and because it is subdivided with each reproductive step away from a given ancestor, the precise degree to which two persons share common heredity can be calculated, and "distance" can thus be stated in specific qualitative terms. (...) People who are blood relatives share a common identity, they believe. This is expressed as "being of the same flesh and blood." (Schneider 1968: 25)

Nonetheless, according to Schneider, this is merely an apparent contradiction in his argument, one prompted by too literal an interpretation of Americans' way of talk. He offers two main arguments against this parlance being evidence for the hypothesis that the genealogical grid is part of American culture.

Firstly, if the genealogical grid were determinant in calculating genealogical distance, one would predict that Americans have a precise conception of "kinship" distance. But cases like the famous relative and, in addition, the vagueness of the notion of distance tend to show that whether 
someone is considered a close or distant relative is established in conjunction with other categorical variables like social status, class differences, geographical dispersal etc. In other words, the calibration of distance is unstable and exists only at the conglomerate level (see Schneider 1968: 72-75, 1970). More importantly, Schneider argues that these supposed bio-genetic semantic features, which seem to be part of the American conception of "kinship," are symbolic:

The alternate strategy of study which I commended yielded the suggestion that these defining elements of 'blood,' of one flesh and blood, of bio-genetic identity could be understood as symbols which stood for social relationships of diffuse, enduring solidarity. (...) Indeed, at many points the scientific facts sharply contradicted the cultural facts about biology; but the fact that the scientific facts had little or no discernible effect on changing the cultural facts seemed good evidence for concluding that the bio-genetic elements in American kinship were primarily symbolic of something else and hardly relevant to biology as a natural or actual state of affairs. (Schneider 1972: 59)

It must be clear by now that, for Schneider, "kinship" is all about a genealogical conception entertained only in the anthropologists' subculture:

'Kinship' is an analytic category which has been prevalent in anthropology since Morgan first invented it. In the way in which Morgan and his followers have used it, it does not correspond to any cultural category known to man. The closest thing to it is the Western European category of 'family,' but if I am correct in my analysis even that is not close. (...) To speak precisely, the title of my book, American Kinship, is a misnomer. I really did not deal extensively with 'kinship' at the conglomerate level nor did I intend to; in the pure cultural level there is no such thing as 'kinship.' Hence my use of the term 'pure kinship level' is wrong too, which I have tried to suggest by the use of quotes around the word. (Schneider 1972: 50; author's emphases) ${ }^{9}$

\footnotetext{
${ }^{9}$ Of course, from the assumption that kinship does not exist in American culture, there is no valid induction to the conclusion that it does not exist in other cultures - in particular, in non-western cultures. Later, drawing on his ethnographic experience among the Yap and also on the "virgin birth" controversy (see, e.g., Leach 1966; Derrett 1971; Montague 1971; Spiro 1968, 1972), Schneider gives further justification to his general conclusion by trying to show that there isn't a conception of kinship in non-western cultures either: kinship ethnographic descriptions in the anthropological literature have been simply the result of an unreflective imposition of the genealogical grid on the data (Schneider 1984).
} 
Together, the criticisms of Needham and Schneider can be construed as embodying a general theoretical dilemma: if one tries to delimit kinship on the basis of the content of social norms, kinship does not exist; if one tries to delimit kinship on the basis of a folkbiological content, kinship does not exist. Ergo: kinship does not exist.

\section{The Hermeneutic Turn}

Epistemological representations are second order representations that set the criteria for the elaboration and/or justification of first order representations as knowledge. They are normative meta-representations supposed to regulate the distribution of knowledge representations. The aim of this section is to characterize in detail a change of epistemological representations in the anthropological subculture (i.e., a change in the epistemology shared by anthropologists) that was fundamental to the fall of kinship (i.e., that negatively regulated the distribution of kinship representations) - the hermeneutic turn.

The expression 'hermeneutic turn' can be utilized to refer to the general importance acquired by symbolic meaning as an object of inquiry since the beginning of the 1960s. Even discounting the unique spin that each anthropologist puts on the definition of the expression 'symbolic meaning,' its more conventional senses may lead to different (but not necessarily incompatible) interpretations of this first sense of the turn: (i) a move to the study of the ideational in its own right, that is, meanings without their being subordinated to any more basic determinant; (ii) a move to the study of a type of ideational, that is, the meanings involved in apparently irrational beliefs and behaviors; (iii) a move to the study of another type of ideational, that is, the meanings motivated by relations such as resemblance, contiguity, opposition or inversion. While some decrease of interest in kinship may be correlated with a stress on some of these notions of symbolic meaning, I hypothesize that this was not an important causal factor in the fall of kinship. Levi-Strauss, for example, discontinued his affair with kinship by assuming a forefront interest in the symbolic not because he concluded that kinship wasn't a worthwhile subject, but simply due to his primary interest in the study of the human mind:

This first experience [the one related to the book "The Elementary Structures of Kinship"] was insufficient because in the domain of kinship the constraints 
are not purely internal. What I mean is that it is not certain that they have their origin in the structure of the mind: they may be the result of the exigencies of social life, and the way it imposes its own constraints on the operation of thought. (Levi-Strauss 1963: 630; my translation)

The hermeneutic turn that is relevant to explain the demise of kinship, even if it incorporates an emphasis on the symbolic, is a more fundamental change related to the theoretical ambitions of anthropology. The project of a generalizing and explanatory science once was legitimate in the anthropological mainstream, and sometimes was even understood in terms of a strong continuity with the natural sciences:

My view of natural science is that it is the systematic investigation of the structure of the universe as it is revealed to us through our senses. There are certain important separate branches of science, each of which deals with a certain class or kind of structures, the aim being to discover the characteristics of all structures of that kind. So atomic physics deals with the structure of atoms, chemistry with the structure of molecules, crystallography and colloidal chemistry with the structure of crystals and colloids, and anatomy and physiology with the structures of organisms. There is, therefore, I suggest, place for a branch of natural science which will have for its task the discovery of the general characteristics of those social structures of which the component units are human beings. Social phenomena constitute a distinct class of natural phenomena. (Radcliffe-Brown 1952: 190)

Subsequently, the mainstream's legitimate aim shifted to one of interpreting single cultures, with an eye towards neither cross-cultural generalization nor explanations, as is reflected in these passages from the most important catalyst of the turn: ${ }^{10}$

The concept of culture I espouse (...) is essentially a semiotic one. Believing, with Max Weber, that man is an animal suspended in webs of significance he

${ }^{10}$ In what follows, rather than an overall interpretation of Geertz's epistemological claims, my characterization of the hermeneutic turn selects the aspects of his claims (and the claims of other comrades) that illustrate the new epistemology that became predominant. In Britain, Evans-Pritchard headed in a similar direction: "It [anthropology] studies societies as a moral systems and not as natural systems (...), it therefore seeks patterns and not scientific laws, and interprets rather than explains" (Evans-Pritchard 1962: 26); "There's only one method in social anthropology, the comparative method - and that's impossible" (cited in Needham 1975: 363). 
himself has spun, I take culture to be those webs, and the analysis of it to be therefore not an experimental science in search of law but an interpretive one in search of meaning. It is explication I'm after, construing social expressions in their surface enigmatic. (Geertz 1973: 5)

(...) the essential task of theory building here is not to codify abstract regularities but to make thick description possible, not to generalize across cases but to generalize within them. (...) Rather than beginning with a set of observations and attempting to subsume them under a governing law, such inference begins with a set of (presumptive) signifiers and attempts to place them within an intelligible frame. (Geertz 1973: 26)

The way this turn contributed to the fall of kinship will be the subject of the final section; what is important here is to give a definite characterization of it.

First of all, the hermeneutic turn should not be conflated with the epistemological question of intertheoretical relations between anthropology, psychology and biology, namely, the extent to which the substantive claims put forward by psychologists and biologists are regarded as pertinent to explain socio-cultural phenomena. There are two general positions on this matter: emergentists and interactionists. Emergentists, in one version or another, embrace the postulate that was fundamental to the birth of autonomous social sciences: "The determining cause of a social fact should be sought among the social facts preceding it and not among the states of individual consciousness" (Durkheim 1982[1895]: 110). ${ }^{11}$ And here is an anthropologist's endorsement: "culture is a thing sui generis which can be explained only in terms of itself... Omnis cultura ex cultura" (Lowie

\footnotetext{
${ }^{11}$ Notice also Durkheim's rejection of the relevance of biology to kinship in the previous section. One could counter-argue that a general rejection of biology is not correct in this issue, since the type of functional explanation used by Durkheim and followers seems to have a physiological inspiration. Nonetheless, this is not a question of intertheoretical relations in the technical sense used here (see, e.g., McCauley 1986; Nagel 1961: chapter 11), but simply one of an explanation being modeled on the pattern of another (Nagel 1961: 520). No specific substantive relation can be inferred from this modeling, but only (and not necessarily) the idea of a more abstract mechanism common to both domains. To make this point clear, take the concept of meme as a unit of cultural transmission: it is based on a more abstract version of the mechanism of natural selection, but no substantive similarity is credited between memes and genes; quite the contrary, the concept of meme implies that cultural transmission can be completely independent of genetic transmission.
} 
1966 [1917]: 66). Interactionists, on the other hand, accept the relevance of psychology and biology to the explanation of socio-cultural phenomena, a good example being Levi-Strauss, who not only saw an intrinsic relation between anthropology and psychology, but also envisaged an all-out unity of science:

I believe the ultimate goal of the human sciences to be not to constitute, but to dissolve man. The pre-eminent value of anthropology is that it represents the first step in a procedure which involves others. Ethnographic analysis tries to arrive at invariants beyond the empirical diversity of human societies; and, as the present work shows, these are sometimes to be found at the most unforeseen points. (...) However, it would not be enough to reabsorb particular humanities into a general one. This first enterprise opens the way for others which Rousseau would not have been so ready to accept and which are incumbent on the exact natural sciences: the reintegration of culture in nature and finally of life within the whole of its physico-chemical conditions. (Levi-Strauss 1966[1962]: 247)

The emergentist conception has been prevalent in anthropology, and the hermeneutic turn simply rephrased it in more semiotic terms: ${ }^{12}$ "Culture, this acted document, thus is public, like a burlesqued wink or a mock sheep raid. Though ideational, it does not exist in someone's head; though unphysical, it is not an occult entity" (Geertz 1973: 10).

What is intrinsic to the turn is a meta-theoretical prescription behind the notions of symbolic meaning, the knowledge to be produced, and interpretation, the means of translation of such knowledge. Interpretation is founded on a semiotics that should drive the methodology of anthropology away from the natural sciences, towards the humanities (see Geertz 1983). This direction can be highlighted by a contrast with Levi-Strauss' opposite inclination:

The anthropologists are in a very peculiar situation in relation to linguistics. For many years they have been working very closely with the linguists, and all of a sudden it seems to them that the linguists are vanishing, that they are going on the other side of the borderline which divides the exact and natural sciences on the one hand from the human and social sciences on the

${ }^{12}$ But see Lawson \& McCawley 1996 and Sousa 1998, for a discussion of the logical implications that the hermeneutic turn has for the question of intertheoretical relations. 
other. All of a sudden the linguists are playing their former companions this very nasty trick of doing things as well and with the same sort of rigorous approach that was long believed to be the privilege of the exact and natural sciences. Then, on the side of the anthropologist there is some, let us say melancholy, and a great deal of envy. We should like to learn from the linguists how they succeeded in doing it, how we may ourselves in our own field, which is a complex one - in the field of kinship, in the field of social organization, in the field of religion, folklore, art, and the like - use the same kind of rigorous approach which has proved to be successful for linguistics. (Levi-Strauss 1963[1956]:69-70)

Symbolic meaning is a type of knowledge that should not involve generalizations and explanations. I elaborate on this denial of generalizations and explanations in turn.

The notion of generalization represents a continuum which may be broken into a crescendo of degrees: an ethnographic description of a single society, regional generalizations which compare cultures of a certain area (e.g., African political systems), generalizations which are on the orbit of the distinction between the "traditional/primitive" and the "modern/western" (e.g., classificatory versus descriptive kinship terminologies), and generalizations which purport to be universal on some level (e.g., the incest taboo). For this reason, by tracing oppositions within different portions of this continuum, and being selective about what is the important part of the work of specific anthropologists, it is always possible to portray the history of anthropology as an everlasting struggle between "relativists" and "universalists," both in the context of different domains of research (e.g., substantivists versus formalists in economic anthropology), and in the context of different traditions (Malinowskians versus Radcliffe-Brownians, Durkheimians versus Levi-Straussians, and Boasians versus non-Boasians). But in order to do that, one has to forget, for example, that Malinowski had extreme theoretical ambitions too, that Raymond Firth was at the same time a main Malinowskian in his ethnographic style and the father of formalism in economic anthropology, and that both Durkheim and LeviStrauss were interested in elementary structures, which they thought could be inferred even from the study of a single simple case.

Without denying that there is some value in these ad hoc oppositions, and that the knowledge produced by anthropologists may be localized in different levels of the generalization continuum, this picture does not 
capture the fundamental rupture of the hermeneutic turn. What is at stake here is a change in the conception of the possibilities of anthropological knowledge - it is a meta-change that prescribes the knowledge that should be produced. Did the mainstream epistemological position before the 1960s proscribe the possibility of going beyond ethnographic descriptions? Take for example, Franz Boas, an anthropologist whose work is surely on the relativist side of the generalization crescendo. Would he deny the prospect of going further? Not really, since his relativism was a step back against simplistic evolutionist generalizations, rather than a principled epistemological rejection of generalizations:

The immediate results of the historical method are, therefore, histories of the cultures of diverse tribes which have been the subject of study. I fully agree with those anthropologists who claim that this is not the ultimate aim of our science, because the general laws, although implied in such a description, cannot be clearly formulated nor their relative value appreciated without a thorough comparison of the manner in which they become manifest in different cultures. But I insist that the application of this method is the indispensable condition of sound progress (...) When we have cleared up the history of a single culture and understand the effects of environment and the psychological conditions that are reflected in it we have made a step forward, as we can then investigate in how far the same causes or other causes were at work in the development of other cultures. Thus by comparing histories of growth general laws may be found. (Boas 1982[1896]: 278-279)

Thus, although, as an attempt to secure the relevance of anthropology in the context of the social sciences and of an ethnography in the context of anthropology, the "Bongo-Bongoism" and "the search for the exotic" have always been around, the gist of the turn lies herein: in the beginning, the mainstream epistemological position did not rule out going beyond ethnographic descriptions, but afterwards the prescription became one of reducing anthropology to thick descriptions, of reducing anthropology to a type of ethnographic enterprise. In this sense, what is implied by the shift is not simply a step back against the simplistic laws eventually brought out by an ideal of a natural science of society: cross-cultural generalizations are now to be seen as trivial deformations of the native's point view, and no form of light may be envisaged at the end of the tunnel.

Leaving aside explanations of single events (e.g., the death of captain Cook), explanations in anthropology deal with a regularity continuum par- 
allel to the generalization continuum described above, in which case I divide the continuum into regularities in a given society (cultural regularities) and regularities across societies (cross-cultural regularities). Not to put too fine a point on it, in the case of explanations of regularities, to explain is to identify the causal factors that contribute to the reoccurrence of the each token of a regularity. Since the rejection of cross-cultural generalizations implies the nonexistence of significant cross-cultural regularities, I comment merely on the hermeneutic rejection of explanations at the cultural level.

Why meaning instead of cause in dealing with human cultural action? An action is made up of two components: one ideational, another behavioral. To explain an action is to take the ideational component as a causal factor whose effect is the behavioral component. For example, in an act of winking, the intention to convey a certain message is viewed as a causal factor whose effect is the behavior of closing and opening the eyelids. From a hermeneutic point of view, this causal construal of the relation between the ideational component and the behavioral component is misleading. Intentions (or reasons in general) are not really causes of actions, they are instead analytically connected to the identity of the action being described - the closing and opening of the eyelids is a wink if and only if the intention to convey a certain message is present. The ideational and behavioral elements are not two separable elements in a relation of cause and effect; they are in a logical relation of definiens to definiendum instead (see Rosenberg 1995). For this reason, the text analogy is the most appropriate, for each ideational element gives the meaning of a specific behavior, and hence constitutes the specific action. In other words, the ideational and the behavioral elements are two sides of the same coin the symbol. This passage from another influential contributor to the turn illustrates this point well:

As structured relationships of symbolic freedoms, cultures are relative and historical forms of life, each having a particular validity without some universal necessity. Hence the character of our cosmographic explications, their sufficiency without necessity, which consists in their being of the nature of logico-meaningful motivations of the practice in question. Physical things have causes, but human things reasons - symbolically constructed reasons even when they are physically caused. And this makes anthropology a science of another kind, different from the natural sciences, because its object and method are of the same kind. (Sahlins 2000: 28-29) 
Moreover, because this system of symbols constitutes an emergentist shared code (one that "does not exist in someone's head"), human actions have regular occurrence in a given society. Finally, because this shared code is evinced not only in actions but also in all other public productions, all culture is to be decoded via the same interpretive rationale.

\section{The Epidemiological Explanation}

Criticisms of a theoretical concept are a possible causal factor in endangering its attractiveness, and so are atheoretical epistemologies, for the downgrading of theories in general may depreciate any theoretical concept in particular. In this section, I consider whether and how these two types of factors, as discussed before, played a causal role in the fall of kinship, as a theoretical concept in anthropology. In this way, I'll delineate an epidemiological explanation of the fall of kinship in anthropology - what is it all about?

It is important to notice first that one of the factors may not be causally significant. In particular, since the rejection of a specific theoretical concept does not presuppose in effect an atheoretical position, the hermeneutic turn may not have had any causal role. Actually, neither Needham nor Schneider assumed in principle an atheoretical position:

Comparison stands a better and quite different chance of success if it is conducted in formal terms. (...) Here we have formal properties which can be defined in purely formal terms, e.g., in the notation of symbolic logic, without reference to any classes of entities, however the classes may be composed, or to the characteristic empirical features of their members. (Needham 1976: $365)^{13}$

It is unnecessary to raise the old problem of how it is possible for two things to be compared as wholes when each is wholly unique. We are spared this burden by the fact that the basis for comparison is give by our definition of culture as a system of symbols and meanings. Symbols and meanings can be compared just as easily as modes of family organization, the roles of seniors to juniors, or the methods of agriculture. (Schneider 1972: 48)

${ }^{13}$ If the later Wittgenstein (1953) was the inspiration for Needham's criticisms, his reconstructive side seems to go in the direction of the early Wittgenstein (1922). 
I do not rule out the possibility that there are universals. But I do rule out the attempt to state them a priori and the attempt to infer them from common sense and the so-called facts of life. (Schneider 1976: 211) (Emphasis added)

Nonetheless, from an epidemiological point of view, more important than the fact that some authors have rejected the concept of kinship without assuming an atheoretical position, is the fact that, if there was a hermeneutic turn in anthropology as characterized, more and more anthropologists accepted an atheoretical position, which suggests at least some kind of mutual influence - the criticisms of kinship confirming the hermeneutic postulates, the atheoretical position augmenting the acceptability of the criticisms.

But even then, it is still possible that in reality the hermeneutic turn was not causally operative, whereas specific epistemological claims need not necessarily guide the elaboration and/or justification of knowledge. Actually, Geertz seems not to have abandoned the concept of kinship completely:

"Kinship" turns out to be a variety of social idiom, a way of talking about and understanding, and thus shaping, some aspects of social life. (...) symbolism arising out of the experience of living as a child, spouse, parent, and elder in a small, walled yard of pavilions, kitchens, granaries, toilets, and altars with a dozen or so familial others does not determine the whole. But neither, as we trust we have shown, does it leave it untouched. (Geertz \& Geertz 1975: 169)

Indeed there need not be any causal link between the epistemological claims put forward by social scientists and their knowledge production. ${ }^{14}$ As I said before, epistemological representations are normative metarepresentations that set the general criteria of acceptability of representations as knowledge. Ideally, they would have a strong selective role in the distribution of knowledge representations: if representations are in accordance with a specific epistemology, they should be accepted as knowledge and become widespread amongst those who advocate the epistemology, otherwise they should be rejected and die out (or, simply leave traces in artifacts that no one ever reads). But in reality, oftentimes social scientists do not follow their proclaimed epistemology - e.g., Durkheim assumed

\footnotetext{
${ }^{14}$ For a related discussion in the context of the natural sciences, see Feyerabend 1988 and Laudan 1984.
} 
an emergentist position but built his theory of religion on the notion of the sacred, which is defined in terms of psychological states such as awe. Therefore, given this freedom to contradiction, hermeneutic anthropologists could have pursued some theoretical constructions of kinship anyway. Epistemological representations may not have a neat causal role in this respect for another reason: frequently they are vague and hence susceptible to different interpretations. It may be that the hermeneutic claims do not specify the exact theoretical level that should be avoided, and that anthropologists sometimes interpret them as not so radically atheoretical. For example, anthropologists could have maintained certain basic theoretical concepts like economy, religion and (why not?) kinship as an intelligible frame that makes thick description possible.

Either way, ultimately the hermeneutic turn might not be a causal factor, or might be simply a meager one, which could be neglected without much explanatory ado. In this case, the problems of kinship theory per se, as pointed out by Needham and Schneider, should be regarded as the relevant causal factor in the decrease of interest in kinship. From now on, I shall argue that, on the contrary, the hermeneutic turn did play a fundamental causal role. I start by putting forth some doubts about the "causal sufficiency" of the criticisms of kinship theory - while undeniably an important factor, the criticisms do not seem to constitute a sufficient explanation in and of themselves.

One type of problem is that, although many of Needham's and Schneider's criticisms were sound, they do not seem to call for an extreme and unified conclusion. Their criticisms are normally interpreted as a common force against the existence of kinship. This is an intriguing fact in itself, because they are based on quite different premises of would-be kinship concepts. Why this perception of alliance against kinship? Why not accept one line of argument and reject the other, and then criticize the former? It is possible to accept Schneider's basic orientation and then show some weakness and vagueness that undermines Schneider's sweeping conclusions.

Regarding Schneider's idea that even in American culture there is no conception of kinship, mentioning three qualms should suffice. ${ }^{15}$ It is

${ }^{15}$ For a more complete discussion of Schneider's approach, see Scheffler 1976, 1991, $2001 \mathrm{a}$. 
doubtful that Americans naturalize nationality in the way they naturalize kinship, and therefore that they do not distinguish kinship from nationality at the pure level. The use of the adjective 'naturalized' to refer to citizens affiliated simply by law suggests, pace Schneider, that there is a different sense of 'natural' in question - becoming a citizen by law immediately incorporates some sense of becoming natural. Besides, if Americans conceptualize kinship at the conglomerate level as Schneider himself recognizes, if the distinction between conglomerate and pure levels is a theoretical artifact of the analyst (not one made by the native), and if the aim is to capture the native's point of view, the self-defeating conclusion seems to be that Americans do conceptualize a notion of kinship. Finally, as far as Schneider's symbolic hypothesis is concerned, even Americans many a time cannot grasp it: " (...) the cultural aspects of action are particularly subtle, sometimes particularly difficult to comprehend partly because they are symbols not treated usually as symbols but as true facts. So it is difficult at times to convince an American that blood as a fluid has nothing in it which causes ties to be deep and strong." (Schneider 1972: 48) ${ }^{16}$

In this case, a less radical interpretation of the conclusion "kinship does not exist" would be that it does not exist outside the US. But, as Schneider admits in his postscript to American Kinship, another yet more tepid interpretation is possible: "I tried to show that "kinship" as a thing, as an object of study, was at best only possible in a very restricted sense, and then probably only in Western cultures such as that in the United States. This is the more conservative, temperate statement of the message (1980: 119)." In this case, kinship would not exist outside western cultures. Last but not least, since Schneider analyzed only one non-western culture

${ }^{16}$ There is a kind of dilemma in Schneider's interpretation here: if Americans accept that in fact (i.e. literally) blood is a deep and strong natural substance that determines kinship relatedness, by definition blood is not a symbol of anything; if Americans accept that symbolically blood is a deep and strong natural substance that determines kinship relatedness, blood is not a symbol of enduring solidarity as Schneider wants, but of a deep and strong natural substance. One way out of this dilemma is a precise psychological characterization of a more general notion of shared natural essence as the basis of the computation of relatedness in kinship (see Hirschfeld 1986): some Americans may identify blood with this essence; others take blood as a symbol of this essence. This notion of essence may have implications to the moral domain (see Bloch \& Sperber 2002), but it is not a symbol of enduring solidarity. 
in detail (but see Kuper 2000: 146-158), there is the even more favorable rendering that kinship is not universal, which leaves open the possibility of it being somewhat pervasive in non-western cultures. Therefore, given the vagueness of the conclusion, why have anthropologists tended to go for the interpretations that deny any importance to kinship? Doesn't this do kinship an injustice?

Another type of problem appears when the broader distribution of basic theoretical concepts in anthropology is taken into account. One of the general lessons to be drawn from Needham's and Schneider's criticisms is that the traditional anthropological partition of its object into basic domains is to be disposed of:

if a colleague tells you that he is interested in kinship, his choice of phrase implies that he could have stated instead that he was keen on subsistence economies or primitive law, and the word he actually employs does indeed give you a vague idea of his theoretical bent, the books he has read, and the kind of technical conversation he is likely to engage you in. In this case as well, however, it cannot be inferred that his interest in kinship will be unconnected with economics or law; and in fact, of course, it will probably turn out that he has to deal with these topics also and that they in turn demand a recourse to kinship. (Needham 1971: 4-5)

To my mind, it will no longer be acceptable to consider 'religion as a cultural system' any more than it would be acceptable to consider 'kinship as a cultural system' or 'politics as a cultural system.' Each culture must be approached apart from its institutional segments, it social organizational segments, or its social structural segments, and from a purely cultural perspective. (Schneider 1972: 60)

If the criticisms advanced by Schneider and Needham had such a driving force, it seems that all traditional basic domains should have been dissipated. But what happened in fact, as mentioned in the introduction, was the progressive incorporation of kinship into other basic domains. So, why weren't these other admittedly problematic domains diluted as well? And why such an attempt to hide kinship-related phenomena in their province? In addition, similar criticisms were directed specifically at some other basic theoretical concepts - e.g., Needham analyzed the concept of belief in similar terms (see Needham 1972), and the concept of gender was approached a la Schneider (see Collier \& Yanagisako 1987). But these criticisms do not 
seem to have had any causal influence in the fortune of these concepts. Then, why did similar causes have different effects for kinship? Why such partiality?

Granted, these doubts do not constitute knockdown arguments, but they do point to an alternative. I've been employing metaphors that call forth the idea that some anthropologists have allied to persecute kinship, and others have been uncomfortable with studying phenomena traditionally identified as part of kinship. My main aim though was simply to suggest that there is something more against the concept of kinship than the arguments raised by the kinship skeptics; and the hypothesis is that this has to do with the hermeneutic turn. I explicate now the overall explanatory picture that springs up from this hypothesis.

The real import of the hermeneutic turn is to be understood in the context of its implications for how anthropologists conceive the identity of anthropology as a discipline, and hence for their personal identity as anthropologists. For this reason, it is necessary to discuss the categorization involved in this construction of identity. Take this graph:

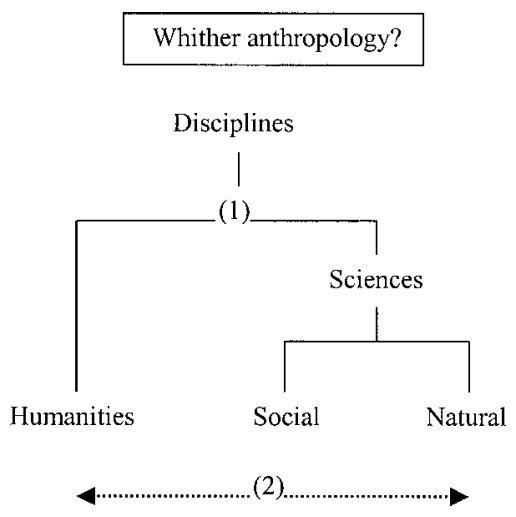

On the one hand, the tree (1) signals that disciplines are classified in some discrete categories organized in a taxonomic structure - e.g., sociology, as the name indicates, is a social science, and biology, a natural science. The identification of a discipline with one of these categories is stable at the institutional level, but essential to my discussion are the current epistemological positions existent in each discipline, which may or may not be in accordance with the established identification, and, in the latter case, may even drive researchers to fight for a change in the institutional 
landscape. On the other hand, the line (2) at the bottom indicates that there is some concurrent fuzziness in this categorization, which is related to the perception of different levels of scientificity. This fuzzy perception may occur not only in relation to specific disciplines - e.g., biology being further to the right than psychology, - but also in relation to specific theoretical traditions in each discipline - e.g., behaviorism being further to the right than psychoanalysis in psychology.

These two characteristics, the taxonomic and fuzzy traits, suggest that something akin to what has been called 'prototype' in the psychology of categorization is part of this process of classification. ${ }^{17}$ Restricting the discussion to the ambit of anthropology, particularly relevant to my concern is the set of features that compose the prototype of a theoretical enterprise aspiring to reach the right end of line (2) - the prototype of the ideal of a natural science of society. One hypothesis is that this prototype comprises the notions of formal precision, positivistic neutrality, lawful regularity and natural causality that are invoked respectively by the features of the following dimensions:

(a) Type of language: the use of formal languages in general and/or mathematical languages in particular.

(b) Type of methodology: the use of formal analysis and/or statistical methods.

(c) Scope of knowledge: the construction of generalizing typologies and laws.

(d) Type of explanation: beyond the use of explanations with social causes, the use of explanations with psychological or biological causes.

Each of these dimensions can be a matter of degree. It is important to comment on the more complex last dimension though. Even if anthropologists tend to interpret the ideational as an emergent cultural level independent of psychology, when the ideational is compared to the folk mind-body dualism generally assumed by social scientists, it is still more related to the

${ }^{17}$ For a discussion of prototypes and other current theories of concepts, see Medin 1989 and Smith \& Medin 1981. Some authors introduce a distinction between core categorization and identification procedures that may be relevant to a more precise psychological characterization of the process of categorization involved here (for a discussion see Smith et al. 1984), but this is beyond the scope of this article. 
mind than to the body. That's why it is not difficult to find anthropologists phrasing their subject as "how natives think," even when they are making cultural descriptions that are not supposed to deal with psychological facts. Therefore, the appeal to biological causes invokes more the notion of a natural science of society than the appeal to psychological causes. This is also reflected in the perception of the causal weights put on the different dimensions of the social. For example, a weight on economy will invoke more the natural than a weight on politics, because economy is more related to the infrastructure (and therefore to the subsistence of the body), and politics is more related to the superstructure (and therefore to the ideational). Ecological explanations that make use of a biological notion of adaptation will invoke even more directly the notion of a natural science of society. The limiting case probably is sociobiology.

Other things being equal, the more a theoretical enterprise shows the features of the prototype, the more it will be perceived as a project whose aim is the constitution of a natural science of society. But there is a perspectival variable calibrating this perception as well, for the same theoretical enterprise may be perceived differently according to the epistemological position of each anthropologist. For example, a theoretical enterprise that somewhat matches the prototype will be perceived as the pursuit of a natural science of society by someone who thinks the identity of anthropology should be positioned more to the side of the humanities, but not necessarily so by someone who thinks its identity should be positioned simply on the place of the social sciences.

Now, before the hermeneutic turn, the mainstream epistemological position in anthropology tended to identify anthropology with the sciences - mainly as a social science distinguished from the natural sciences, but many times as a social science that should strive in the direction of the natural sciences. But the adherence to hermeneutic epistemological claims pushed the identity of anthropology in the direction of the humanities. Anthropologists have to conciliate being scientists and being in permanent flirtation with the humanities. For this reason, in the right end of line (2), hermeneutists have their great antagonist - beyond an atheoretical position, the hermeneutic turn entails an anti-ideal-of-a-natural-science-of-society. In other words, the hermeneutic turn is a negation of all features of the prototype described above. 
Also, by the $1960 \mathrm{~s}$, and just concomitant with the start of the turn, kinship studies seemed to have reached a scientific apex. A sophisticated formal (at times mathematical) language to describe kinship genealogies and terminologies, a rigorous formal methodology to analyze the semantic of kinship terms, and a host of typologies and theoretical laws about kinship classifications and their relations to social structure had been advanced. In the British tradition, descent theorists, under the guidance of functionalstructuralism, focused on the functional laws of descent groups and their contribution to social equilibrium (see, e.g., Radcliffe-Brown 1950; Fortes 1953). In the French tradition, alliance theorists, under the guidance of structuralism, dealt with the principles of alliance between descent groups implied by different rules of marriage and somewhat correlated with different kinship terminologies (see, e.g., Levi-Strauss 1969[1949]; Dumont 1953). In the American tradition, Murdock furnished an account to the laws of kinship systems and their relation to social structure, buttressed by cross-cultural statistical tests (see Murdock 1949), and formal approaches to the study of kinship semantics were developed as part of the school of ethnoscience, which later became cognitive anthropology (see, e.g., Goodenough 1956; Lounsbury 1964).

And, even if not all kinship authors just mentioned saw their theorizing as the pursuit of a natural science of society (from the perspective of many, it meant simply one of a social science of society), the area of kinship studies became identified in the minds of anthropologists with a hermeneutic perspective as a theoretical enterprise pursuing the right end of line (2). The point in this epidemiological approach is neither whether kinship studies were really about to achieve an ideal of natural science of society, nor whether kinship studies were perceived to be really about to achieve an ideal of a natural science of society, but rather that kinship studies became identified as the carrier of a project with such an intent in the mind of those who thought the identity of anthropology should be positioned more to the side of the humanities.

So, the additional element in explaining the decrease of interest in kinship is the conclusion of the following argument. With the hermeneutic turn, more and more anthropologists tended to identify anthropology as a project that should be coupled with the humanities, away from the natural sciences; because kinship had always been strongly associated 
with the identity of anthropology in itself, and because kinship became strongly correlated with the above prototype, it became the symbol of anthropology attempting to go in the direction of the natural sciences; therefore: kinship became unattractive for more and more anthropologists, since it became the symbol of anthropology aiming in the right direction, namely, the wrong direction. I hypothesize that this symbolic association in the mind of individual anthropologists is a fundamental (albeit perhaps not fully conscious) factor in the decrease of interest in kinship. This factor interacted with the existing criticisms of kinship theory by making them more acceptable, by channeling their interpretation to more extreme conclusions, and also by making the countercriticisms that eventually appeared ignorable.

This type of explanation predicts a second stage in the decline of interest in kinship. The hermeneutic epistemology was widespread by the beginning of the 1980s, but there was an important development afterwards:

Rosaldo noted that in the 1970s, Geertz was preaching the blurring of disciplinary boundaries, the "reconfiguration of social thought," and he rather fancifully suggested that there was a connection between Geertz's advocacy of interpretive ethnography and the New Left's adoption of a rainbow coalition of minority causes. As Rosaldo saw it, the "reorientation of anthropology was itself part of a series of much broader social movements and intellectual reformulations." Be that as it may, Geertz's writings had formed the new generation of anthropologists, just as much as their flirtations with the New Left. Those who elected to follow an academic career had prudently written conventional interpretive ethnographies. But Geertz's advocacy of literary theory did offer an opening toward a more radical reorientation. Providentially enough, exciting new literary theories now appeared, as "deconstruction" swept through the departments of literature. It is therefore not altogether surprising that the next turn in American anthropology was toward an extreme relativism and culturalism, the program of Geertz, but stripped of all reservations. (Kuper 1999: 205-206)

There was no strong homogeneity among the authors of the post-modern movement mentioned in this quotation ("the next turn in American anthropology" - see, e.g., Clifford \& Marcus 1986), but there was an 
influential general message consonant with broad post-modern convictions - an extreme particularism and an extreme relativism. ${ }^{18}$

The extreme particularism is a further extension of the hermeneutic atheoretical stance. Beyond the rejection of knowledge professing regularities across societies (cross-cultural regularities), it involves a dismissal of knowledge portraying regularities within a specific society (cultural regularities). It is the very notion of culture with its implications of temporal stability, homogeneity, and holistic integration that should now be considered theoretically unsound, since in reality societies are completely dynamic, internally diversified and fragmentary. ${ }^{19}$

The extreme relativism is a further extension of traditional cultural relativism. Most anthropologists tend to be relativists concerning the truth of other peoples' beliefs. People of each different society live in a culturally constructed world and have true beliefs according to their culturally constructed world - no epistemological justification exists for assuming that the western scientific description of the world is more accurate than a religious description found in a non-western society, for example. But at the same time most anthropologists tended not to be relativists concerning the possibility of their interpretation of other peoples' beliefs being accurate, which is actually a necessary condition for the first type of relativism, since to postulate a plurality of culturally constructed worlds, one has to accept the possibility of achieving real knowledge of the different culturally constructed worlds. The post-modernist position is that all claims to knowledge lack rational foundation. ${ }^{20}$

18 'Particularism' here is related to the scope of possible knowledge - it is a denial of generalizations or universals; 'relativism' related to the possibility of knowledge - it is a denial of the difference between accurate and non-accurate descriptions of the world (or of the difference between more accurate and less accurate descriptions of the world). In anthropology, the term 'relativism' is normally used in these two senses, but no necessary connection exists between them: one can deny the possibility of generalizations and yet assume the possibility of some particular descriptions being accurate, others not.

${ }^{19}$ Since the beginning of the seventies, there had been criticisms pointing out that the essentializing implications of the traditional concept of culture made it irrelevant (Ortner 1984). The post-modernist extremist implication is not simply that the traditional concept of culture is invalid, but that no concept of culture can be valid.

${ }^{20}$ Since the beginning of the seventies, there had been reflexive criticisms questioning the ideological basis of anthropological knowledge - the links between anthropology and colonialism/imperialism (see, e.g., Asad 1973; Hymes 1974) and the masculine point of view 
The outcome of a thoroughly fluid object of study and an entire absence of objectivity is a project whose aim is to reduce anthropology to literary experimentation or political demystification, two somewhat different trends of post-modernism. The extent to which these antiepistemological norms were coherently followed, and to which the post-modern project was effectively realized is not the important point here. What is fundamental is the implication for the personal identity of anthropologists and their perception of scientific projects. If the hermeneutic turn implied a tension between being coupled with the humanities and being still a scientist, the post-modern movement tended to release the cognitive dissonance: anthropologists became unconstrained, qua anthropologists, in their pursuit of political and literary ventures. At the same time, the post-modern perspective increased the anti-scientific bias among anthropologists: the right direction became more like the right political direction, and the signs of science lost all their aesthetical enticement. For all this, my explanation entails that the post-modern movement introduced a further decrease of interest in kinship.

The main predictions or retrodictions of the explanation can be summarized as follows: wherever hermeneutic or post-modernist claims became widespread and important amongst anthropologists, there should be a significantly correlated decrease of interest in kinship (and even stronger in the post-modern case). Thus far, this "wherever" has been understood in the general context of anthropology, but it can be understood in the more specific contexts of the different traditions or schools of anthropology. For example, although the hermeneutic and post-modern claims reached a wide distribution in anthropology, they originated mainly (and were more influential) in the American tradition; therefore the prediction is that kinship became more unattractive in the American tradition than in the other traditions. On another level, although more widespread in the American tradition, the claims were not catchy for a school such as cognitive anthropology, and the prediction is that there has been no significant decrease

of ethnographic descriptions (see, e.g., Rosaldo \& Lamphere 1974). On the other hand, the emphasis put on interpretation by the hermeneutic turn implied also that anthropological knowledge is not a matter of direct observation. The post-modernist extremist implication is not simply that a positivistic conception of knowledge is invalid, but that no epistemic concept of knowledge can be valid. 
of interest in kinship in this school. In the end, the most precise prediction is this: in any random sample of anthropologists there will be a significant correlation between their being influenced by hermeneutics or post-modernism and their thinking that there cannot exist any theory of kinship.

My explanation can also integrate the other relevant facts mentioned previously without much difficulty. That the same criticisms didn't have the same effect in relation to other basic concepts, that the traditional domain of kinship was incorporated by other basic domains instead of a general dissolution, suit the singular symbolic value that kinship has for hermeneutists and post-moderns. The exaggeration of kinship's death is to be understood in the context of an ideological attempt to establish the hegemony of the new epistemological trends and self-image of anthropology, and therefore to reconfigure the distribution of academic prestige in the discipline. It is not only negligence of the work of supposedly conservative anthropologists who insist in studying spurious objects, but also an attempt to assure the death of the myth of a natural science of society.

\section{Conclusion}

Of course, much more empirical research is needed in order to test the adequacy of the hypotheses and predictions raised here. For this reason, my explanatory picture is not much more than a logical possibility with some plausibility. But I would like to conclude by pointing out another type of limitation, one related to the internal completeness of my explanation as an epidemiological explanation.

A common explanatory picture in anthropology is that the decline of kinship as an object of study is just a result of the progress of knowledge of the discipline, which converged to the conclusion that Homo sapiens is a special species whose behavior and thought cannot be understood in causal terms and whose only specific and substantial commonality is the symbolic capacity to realize different cultures. The point of interest for my final remark is that this picture entails an explanation for the spread of the hermeneutic epistemology that is incompatible with my approach - the hermeneutic turn is simply the epistemological conclusion of this development of knowledge about the basic ontology of human 
beings. Even though my explanatory picture envisages that the criticisms of kinship and other basic concepts contributed to the fixation of the hermeneutic epistemology, it entails that this cannot be the whole story. The hermeneutic turn is a necessary additional factor to explain the kinship fall, but something more is also required to explain the hermeneutic rise and its post-modern developments. So, a more complete epidemiology of the spread of hermeneutic and post-modern claims in the anthropological subculture is necessary.

The way to follow should be in line with the general suggestions of Kuper and Rosaldo (see Rosaldo 1989) in Kuper's quotation above: a look at the ideas and values coming from the wider academic context and also from the social movements of the time. In other words, it is important to deal with the broader scope of the distribution of ideas and values that helped to shape the hermeneutic and post-modern claims and that set the ground for their attractiveness by co-opting susceptibilities already existent among anthropologists. In the end, probably, one will have to explain why certain romantic ideas and a certain opposition between rationality and irrationality became so contagious to the western mind.

\section{REFERENCES}

AsAD, T. (ED.)

1973 Anthropology and the colonial encounter. London: Ithaca Press.

Atran, S., Medin, D., Ross, N., Lynch, E., Vapnarsky, V., Coley, J., Timura, G. And Baran, M.

2002 Folkecology, Cultural Epidemiology, and the Spirit of the Commons. Current Anthropology 43/3.

Aunger, R.

2002 The electric meme. New York: The Free Press.

BARNES, J.A.

1961 Physical and Social Kinship. Philosophy of Science 28: 296-299.

1964 Physical and Social Facts in Anthropology. Philosophy of Science 31: 294-297.

BeAtтie, J.H.

1964 Kinship and Social Anthropology. Man 130: 101-103.

BloGh, M. \& Sperber, D.

2002 Kinship and evolved psychological disposition: The Mother's Brother controversy reconsidered. Current Anthropology 43/5: 723-734.

BOAS, F.

1982 [1896] The limitations of the comparative method of anthropology. In Race language and culture. Chicago: The University of Chicago Press. 
BOYER, P.

2001 Religion Explained. Basic Books.

Carsten, J.

2000 Introduction: cultures of relatedness. In J. Carsten (ed.), Cultures of relatedness new approaches to the study of kinship. Cambridge: Cambridge University Press.

Clifford, J. \& Marcus, G.

1986 Writing culture: The poetics and politics of ethnography. Berkeley: University of California Press.

Collier, J. \& YAnagisako

1987 Towards a unified analysis of gender and kinship. In Gender and Kinship: Essays toward a unified analysis. Stanford: Stanford University Press.

DERRETT, J.D.M.

1971 Virgin Birth and the Gospels. Man 6: 289-293.

DuMONT, L.

1971 Introduction a deux theories d'anthropologie - groupes de filiation et alliance de mariage. Paris: Mouton.

DURKHEIM, E.

1982 [1895] The rules of the sociological method. New York: Free Press.

1898 Review of Kohler. L'Annee Sociologique 1: 306-319.

Eriksen, T.H. \& Nielsen, F.S.

2001 A history of anthropology. London: Pluto Press.

EvANS-PRITCHARD, E.E.

1940 The Nuer: a description of the modes of livelihood and political institutions of a Nilotic People. Oxford: Clarendon.

FEYERABEND, P.K.

1988 Against Method. New York: Verso.

Fortes, M.

1945 The dynamics of clanship among the Tallensi. London: Oxford University Press.

1953 The structure of unilineal descent groups. American Anthropologist 55: 17-41.

1959 Descent, filiation and affinity: A rejoinder to Dr. Leach. Man 59.

GELlner, E.

1957 Ideal language and Kinship Structure. Philosophy of Science 24: 235-242.

1960 The Concept of Kinship. Philosophy of Science 27: 187-204.

1963 Nature and Society in Social Anthropology. Philosophy of Science 30: 236-251.

Geertz, H. \& Geertz, G.

1975 Kinship in Bali. Chicago: University of Chicago Press.

Goodenough, W.

1956 Componential Analysis and the study of meaning. Language 32: 195-216.

HIRSGHFELD, L.

1986 Kinship and Cognition: Genealogy and the Meaning of Kinship Terms. Current Anthropology 27/3.

1995 Race in the making. Cambridge: The MIT Press. 
Hymes, D. (ED.)

1974 Reinventing Anthropology. New York: Vintage.

Kroeber, A.L. \& Kluckhohn, C.

1952 Culture: A critical review of concepts and definitions. Papers of the Peabody Museum 47, 1: 1-223.

Kroeber, A.L. \& Parsons, T.

1958 The concept of culture and of social system. American Sociological Review 23: 582583.

Kuper, A.

1982 Lineage theory: a critical retrospect. Annual Review of Anthropology 11: 71-95.

1988 The invention of primitive society: transformations of an illusion. London: Rutledge.

2000 Culture - the anthropologists' account. Cambridge: Harvard University Press.

LAUDAN, L.

1984 Science and Values. Chicago: The University of California Press.

Lawson, T. \& MacGauley, R.

1996 "Who Owns Culture?" Method and Theory in the Study of Religion 82: 171-190.

LEACH, E.

1958 Concerning Trobriand clans and the kinship category tabu. In J. Goody (ed.), The developmental cycle in domestic groups. Cambridge: Cambridge University Press, pp. 120-145.

1961a Rethinking Anthropology. London: Athlone Press.

1961b Pul Eliya, A village in Ceylon. Cambridge: Cambridge University Press.

1966 Virgin Birth. Proceedings of the Royal Anthropological Institute, pp. 39-49.

1967 The language of Kachin kinship: Reflections on a Tikopia model. In M. Freeman (ed.), Social organization: Essays presented to Raymond Firth. Chicago: Aldine, pp. 125-152.

LEVI-Strauss, C.

1963 [1958] Structural Anthropology. Harmondsworth: Penguin Books.

1966 The savage mind. London: Weidenfeld \& Nicolson.

1963 Réponses a quelques questions. L'Esprit 31/11: 628-653.

1969 [1949] The Elementary Structures of Kinship. London: Eyre and Spottiswoode.

LOUNSBURY, F.G.

1964 The structural analysis of kinship semantics. In H.G. Lunt (ed.), Proceedings of the Ninth International Congress of Linguistics. The Hague: Mouton.

LOWIE, R.H.

1966 [1917] Culture and Ethnology. New York: Basic Books.

MaCauley, R.

1986 Intertheoretical relations and the future of psychology. Philosophy of Science 53.

MaCauley, R. \& Lawson, T.

2002 Bringing ritual to mind. Cambridge: Cambridge University Press.

MEDin, D.

1989 Concepts and conceptual structure. American Psychologist 45: 1469-1481.

Montague, S.

1971 Trobriand Kinship and the Virgin Birth Controversy. Man 6: 353-368. 
MORGAN, H.L.

1871 Systems of Consanguinity and Affinity of the Human family. Washington: Smithsonian Institution.

MORRIS, M. ET AL.

2001 Culturally Conferred Conceptions of Agency: A Key to Social Perception of Persons, Groups, and Other Actors. Personality and Social Psychology Review 5/2: 169-182.

NAGEL, E.

1961 The Structure of Science. New York: Harcourt, Brace \& World.

NeEDHAM, R.

1960 Descent systems and Ideal Language. Philosophy of Science 27: 96-101.

1971 Remarks on the Analysis of Kinship and Marriage. In R. Needham (ed.), Rethinking Kinship and Marriage. London: Tavistock Publications.

1974 Introduction. In Remarks and Inventions: skeptical essays about kinship. London: Tavistock Publications.

1975 Polythetic classification: convergence and consequences. Man 10: 349-369.

Nichols, S.

2002 On the Genealogy of Norms: A case for the Role of Emotion in Cultural Evolution. Philosophy of Science 69 (June): 234-255.

OrTner, S.B.

1984 Theory in Anthropology since the sixties. Comparative Studies in Society and History 26: $126-166$.

PARKIN, R.

1997 Kinship: an introduction to basic concepts. Oxford: Blackwell.

PARSONS, T.

1951 The social system. New York: Free Press.

Peletz, M.G.

1995 Kinship studies in late twentieth-century anthropology. Annual Review of Anthropology 24: 343-372.

RADGLIFFE-BROWN, A.R.

1950 Introduction. In R. Radcliffe-Brown \& D. Forde (eds.), African Systems of Kinship and Marriage. London: Oxford University Press.

Rivers, H.R.

1924 Social Organization. London: Keegan Paul, Trench \& Trubner.

Rosaldo, R.

Culture and Truth: The Remaking of Social Analysis. Boston: Beacon Press.

Rosaldo, M. \& LAmphere, L.

1974 Woman, culture, and society. Stanford: Stanford University Press.

Rosenberg, A.

1995 Philosophy of Social Science. Westview Press.

SAHLins, M.

2000 Introduction. In Culture in Practice - Selected Essays. New York: Zone Books. 
SCHEFFLER, H.W.

1966 Ancestor worship in anthropology: or, observations on descent and descent groups. Current Anthropology 7(5): 541-551.

1976 The "Meaning" of Kinship in American Culture: Another View. In K. Basso and H. Selby (eds.), Meaning in Anthropology. Albequerque: University of New Mexico Press.

1985 Filiation and affiliation. Man 20(1): 1-21.

1991 Sexism and Naturalism in the Study of Kinship. In Micaela di Leonardo (ed.), Gender at the Crossroads of knowledge: Feminist Anthropology in the Postmodern Era. California: University of California Press.

2001a Remuddling Kinship: The State of the Art. Zeitschrift fur Ethnologie 126: 161-174.

2001b Filiation and Affiliation. Boulder: Westview Press.

SCHNEIDER, D.

1965 Kinship and Biology. In H.J. Coale (ed.), Aspects of the Analysis of Family Structure. Princeton: Princeton University Press.

1968 American kinship: a cultural account. Chicago: University of Chicago Press.

1972 What is Kinship all about? In P. Reining (ed.), Kinship Studies in the Morgan Centennial Year. Washington: Anthropological Society of Washington.

1976 "Notes Toward a Theory of Culture," in Meaning in Anthropology. Edited by K. Basso and H. Selby. Albequerque: University of New Mexico Press.

1980 Twelve Years Later. In American kinship: a cultural account, 2nd edition. Chicago: University of Chicago Press.

1984 A critique of the study of Kinship. Ann Arbor: University of Michigan Press.

Smith, E.E. \& Medin, D.

1981 Categories and concepts. Cambridge: Harvard University Press.

Smith, E.E., Medin, D. \& Rips, L.

1984 A psychological approach to concepts. Cognition 17: 265-274.

SOUSA, P.

1998 Response to "Who owns 'culture'?" Method E् Theory in the Study of Religion 10: 199-206.

SPERBER, D.

1996 Explaining Culture: a naturalistic approach. Cambridge: Basil Blackwell.

2000 An objection to the memetic approach to culture. In Robert Auger (ed.), Darwinizing Culture: The status of memetics as a science. Oxford: Oxford University Press.

SPIRO, M.

1968 Virgin Birth, Parthenogenesis and Physiological Paternity: An Essay in Cultural Interpretation. Man 3: 242-261.

1972 Virgin Birth. Man 7: 315-316.

Strauss, G.

2000 The culture concept and the individualism/collectivism debate: dominant and alternative attributions for class in the United States. In Nucci et al. (eds.), Culture, thought and Development. Mahwah, NJ: Lawrence Erlbaum.

STrauss, C. \& Quinn, N.

1997 A cognitive theory of cultural meaning. Cambridge: Cambridge University Press. 
Whitehouse, H.

2000 Arguments and icons: divergent modes of religiosity. Oxford: Oxford University Press. Wittgenstein, L.

1922 Tractatus logico-philosophicus. London: Harcourt, Brace.

1953 Philosophical Investigations. Oxford: Basil Blackwell. 